\title{
O QUE É QUE A BAHIA TEM?
}

\section{Lisa Earl Castillo*}

Universidade Estadual de Campinas

Campinas - São Paulo - Brasil

Resenha do livro: ICKES, Scott. African-Brazilian Culture and Regional Identity in Bahia, Brazil. Gainsville: University Press of Florida, 2013.

Nos estudos afro-brasileiros, é reconhecido que a cidade do Salvador exerceu um papel fundamental no desenvolvimento do imaginário acadêmico e popular sobre a identidade baiana e sobre a cultura negra no Brasil de forma mais ampla. Isso se deve, em parte, ao expressivo tamanho da população afrodescendente da velha Cidade da Bahia ao longo da sua história. Mas, a importância da cultura negra na identidade soteropolitana passou a ser examinada por estudiosos apenas no século $\mathrm{XX}$, na esteira das obras pioneiras de Nina Rodrigues e Manuel Querino. As décadas de 1930 e 1940 constituíram-se como um dos períodos mais férteis, quando a produção cultural de intelectuais e artistas como Jorge Amado, Edison Carneiro, Pierre Verger, Carybé e Dorival Caymmi estimulou o crescimento de uma

\footnotetext{
* Doutora em Letras pela Universidade Federal da Bahia. Pesquisadora de Pós-Doutorado no Centro de Pesquisa em História Social da Cultura do Departamento de História da Universidade Estadual de Campinas e bolsista da Fundação de Amparo à Pesquisa do Estado de São Paulo. E-mail: lisa.earl.castillo@gmail.com.
} 
imagem da Bahia como lugar de mistério, magia e alegria, profundamente marcada por uma mistura sui generis do catolicismo popular com a cultura e religiosidade afro-brasileiras. A partir dos anos 1990, esse modo de olhar passou a ser denominado baianidade, tornando-se objeto de numerosos estudos. Entre eles destacamos os livros de Patrícia de Santana Pinho (Reinvenções da África na Bahia. São Paulo: Annablume, 2004) e Agnes Mariano ( $A$ invenção da baianidade. São Paulo: Annablume, 2009). Grande parte dessa literatura tem como preocupação central a música popular, sobretudo a do Carnaval, com ênfase nos anos 1980, quando o sucesso internacional dos blocos afros e o tombamento, pela Unesco, do Pelourinho, o bairro mais antigo de Salvador, como patrimônio arquitetônico da humanidade levaram o governo da Bahia a institucionalizar as manifestações populares afro-baianas desse bairro como pedras fundamentais do turismo cultural.

Porém, as raízes desse tropo da identidade baiana emaranham-se com diversos outros tipos de produção cultural e, como notamos acima, remontam à primeira metade do século XX. Nesse sentido, o livro do historiador Scott Ickes, African-Brazilian culture and regional identity in Bahia, Brazil - fruto de uma tese de doutorado defendida em 2003 e publicada dez anos depois - representa uma contribuição importante aos estudos sobre o tema. Tomando como seu objeto a cristalização desse paradigma regional durante o governo de Getúlio Vargas - justamente quando o resto do Brasil vivenciou o surgimento de uma maneira de conceber a identidade nacional fundamentada na mestiçagem das três raças -, o livro desenha a legitimação, na opinião pública da Bahia, de manifestações culturais outrora rejeitadas e, até, perseguidas. Ao traçar essas mudanças, ao longo de seis capítulos, Ickes analisa a atuação de intelectuais, artistas e governantes, atentando também ao protagonismo de líderes negros. Além de considerar os campos da música popular e do Carnaval, o autor também dedica espaço a outras manifestações culturais, como a capoeira e a religiosidade afro-brasileira.

No primeiro capítulo, Ickes examina o quadro econômico e político de Salvador entre 1930 e 1954. Nesse período, Getúlio Vargas ativamente promovia a industrialização no Sudeste do Brasil, mas não projetava mudança semelhante para o Nordeste. Na Bahia, a agricultura continuava a ocupar seu lugar histórico de espinha dorsal da economia até o início da década de 1950, com a descoberta de petróleo no Recôncavo baiano. Nesse contexto, Salvador mantinha sua antiga importância como porto de exportação de produtos agrícolas e como centro financeiro do estado. Uma das consequências dessa prolongada dependência da agropecuária foi a manutenção de divisões sociais de longo prazo na cidade, entre uma pequena oligarquia cuja riqueza 
veio de fazendas nos interiores ou do comércio associado à agricultura, uma reduzida classe média formada por pequenos comerciantes e funcionários públicos e, finalmente, uma enorme classe trabalhadora. Nessa pirâmide social havia um acentuado caráter racial, com a cúpula ocupada por brancos e mestiços de pele clara e a base por afrodescendentes de pele mais escura.

O segundo capítulo analisa a política cultural de Salvador, com destaque para a atuação de Juracy Magalhães, que chegou à Bahia em 1930 como interventor nomeado por Vargas, sendo eleito governador em 1935. Segundo Ickes, a liderança de Magalhães proporcionou uma nova abertura social à cultura afro-brasileira, sobretudo ao candomblé e à capoeira. Essa atitude, caracterizada pelo autor como populismo cultural (p. 60), se deveu em parte às posturas do próprio interventor, mas, por outro lado, resultou dos esforços de líderes negros que lutaram contra atitudes e leis que discriminavam as manifestações culturais afro-brasileiras. Entre uma série de eventos que marcaram esse processo de abertura, o autor considera três como marcos. Em primeiro lugar, uma exposição pública de capoeira regional por Manoel dos Reis Machado (Mestre Bimba) que ocorreu no próprio palácio do governador, em 1936. Outro evento que se constituiu como um divisor de águas foi a retomada, em 1937, da prática de lavar o interior da igreja do Bonfim durante o festival anual do santo, proibida desde 1890. Poucas semanas depois, houve o II Congresso Afro-Brasileiro, organizado em 1937 por um grupo de jovens intelectuais, entre os quais Edison Carneiro, ele mesmo afrodescendente, com a participação do romancista Jorge Amado e de líderes afro-brasileiros, entre os quais Martiniano do Bonfim, Eugênia Anna dos Santos (Mãe Aninha) e Joãozinho da Gomeia.

No terceiro capítulo, o autor examina com mais detalhe a inserção de manifestações da cultura negra popular no cenário dos festivais do catolicismo popular. Retorna ao tema da Lavagem do Bonfim, mostrando a crescente importância dessa festa e seus elementos afro-baianos, bem como a participação de governantes na Irmandade do Bonfim e na procissão anual. O capítulo examina também as "festas de largo" de Santa Bárbara (comemorado no 4 de dezembro), Conceição da Praia (8 de dezembro), Bom Jesus dos Navegantes (1 de janeiro) e Iemanjá ( 2 de fevereiro), esta última a única cujas características afro-brasileiras não se legitimam através do sincretismo afro-católico. Segundo o autor, a participação popular nesses festivais teria aumentado nos anos 1940, impulsionada pelo crescimento populacional da cidade. Um dos aspectos mais originais deste capítulo é o uso de dados obtidos dos diários de campo dos antropólogos norte-americanos Melville e Frances Herskovits, sobre sua visita à Bahia em 1940-41. Porém, em algumas 
partes, a credibilidade da análise é prejudicada por erros fatuais, como, por exemplo, quando afirma que Santa Bárbara é a padroeira de pescadores (p. 84), que Nossa Senhora da Conceição da Praia é sincretizada com Iemanjá (p. 86) e que a Festa de Iemanjá que acontece no bairro do Rio Vermelho surgiu da festa católica em louvor a Santa Anna (p. 90, n. 41). ${ }^{1}$ Apesar de alguns desses erros serem aparentemente provenientes das fontes originais, para o leitor que entenda do assunto a falta de correções explícitas levanta dúvidas sobre a possível presença de outras incoerências.

O quarto capítulo debruça-se sobre a evolução do discurso da baianidade nos anos 1930-40. Para o autor, a veiculação desse olhar sobre a identidade da cidade do Salvador, apesar de promover aceitação de elementos lúdicos das práticas religiosas afro-brasileiras, manteve estes últimos numa posição subalterna em relação ao catolicismo popular. ${ }^{2}$ A institucionalização dessa visão da cultura baiana envolveu a participação ativa da imprensa local e posicionamentos estratégicos de membros do governo estadual. Nesse capítulo, o autor também dedica atenção especial ao discurso sobre a Bahia nas letras da música popular, não apenas no âmbito local, mas também no cancioneiro produzido no Rio de Janeiro por compositores como Ari Barroso e Dorival Caymmi. Embora sejam convincentes, os argumentos do autor teriam sido fortalecidos por mais diálogo com a ampla historiografia e crítica cultural sobre a representação discursiva da Bahia no samba carioca e as contribuições de compositores e músicos, nascidos na Bahia ou descendentes de baianos, no cenário musical do Rio.

No quinto capítulo, o autor aborda o Carnaval da Bahia durante o governo Vargas. No início dos anos 1930, a festa de Momo na Bahia foi dominada por grandes clubes carnavalescos formados no final do século XIX, que recebiam apoio financeiro do governo para custear as despesas do desfile. Entretanto, esse apoio acabou no final da década de 1930, quando a economia baiana, sentindo as repercussões da II Guerra Mundial, entrou em recessão. Assim, os grandes clubes vivenciaram um período de decadência, o que acabou abrindo espaço para a visibilidade de escolas de samba ou batucadas, oriundas das camadas populares. Os afoxés, agremiações afro-brasileiras vinculadas a terreiros de candomblé, que tinham sido proibidos em 1905, acaba-

\footnotetext{
1 Santa Bárbara é a padroeira dos bombeiros. Quem protege os pescadores é Iemanjá, cuja festa anual no Rio Vermelho, em 2 de fevereiro, surgiu como uma oferenda coletiva pelos pescadores do local, completamente distinta das comemorações para Santa Anna, padroeira do bairro, que acontecem em 26 de julho e que, na mitologia afro-baiana, é associada à orixá Nanã Buruku.

2 Uma versão em português desse capítulo foi publicada na revista Afro-Ásia, sob o título: Era das batucadas: o carnaval baiano das décadas 1930 e 1940. Afro-Ásia, no 47, 2013, p. 199-238.
} 
ram voltando à cena nesse período e, juntando-se às batucadas, contribuíram para um reflorescimento da presença afro-brasileira na folia soteropolitana. Os anos 1950, porém, trouxeram o retorno de alguns dos grandes clubes e, com a invenção do trio elétrico em 1951, o espaço das batucadas e dos afoxés diminuiu. Nesse sentido, Ickes defende que os anos 1940 se destacam como uma época de ouro em termos da participação negra no Carnaval da Bahia.

No sexto e último capítulo, a narrativa se desloca para o papel de alguns artistas e intelectuais na construção do paradigma da baianidade, apresentando as trajetórias de diversos personagens. Algumas são de influência consagrada, como o etnólogo, historiador e fotógrafo Pierre Verger, que chegou a Bahia em 1946 e posteriormente vinculou-se ao terreiro Ilê Axé Opô Afonjá. Outra figura cujas contribuições são reconhecidas é o artista plástico Hector Julio Paride Bernabó, mais conhecido como Carybé, grande amigo de Verger e ligado ao mesmo terreiro. Ambos produziram vastas obras inspiradas na cultura afro-baiana, especialmente suas expressões religiosas. Junto com os romances de Jorge Amado e as músicas de Dorival Caymmi, a fotografia de Verger e os quadros de Carybé alcançaram uma circulação pelo Brasil afora e também no exterior. Neste capítulo, o autor também demonstra a influência de atores menos conhecidos hoje, como o poeta Odorico Tavares, que chegou à cidade como jornalista em 1942, posteriormente tornando-se diretor de dois jornais influentes, o Estado da Bahia e o Diário de Notícias, e de uma emissora de rádio. Outro personagem importante foi Antonio Monteiro, um folclorista e historiador amador vinculado ao candomblé. O autor também ressalta as contribuições de outros membros de terreiros, como o comerciante negro Miguel Santana, ogã do Ilê Axé Opô Afonjá, e Mestre Didi, filho de sangue de Mãe Senhora, ialorixá do mesmo terreiro. Outra pessoa que recebe atenção aqui é o capoeirista Vicente Ferreira Pastinha, o Mestre Pastinha, responsável por uma reafricanização da imagem da capoeira, em contraste ao Mestre Bimba cujo estilo já incorporava elementos emprestados das artes marciais e do boxe. Para Ickes, a produção intelectual e artística desse período estava entrelaçada com um nascente interesse do governo da Bahia em promover um desenvolvimento turístico que visava à cultura negra e popular como uma atração importante. Nesse ponto, o autor diverge de estudiosos anteriores, que tendem a apontar para os anos 1980 como o início desse interesse estatal, a partir do investimento financeiro e administrativo na restauração do Pelourinho como espaço de turismo e da explosão simultânea do Olodum, sediado no mesmo bairro, no cenário internacional de world music.

Um aspecto instigante da trajetória novecentista da cultura negra no Brasil é que, apesar de terem ocorrido processos paralelos no Rio de Janeiro 
e na Bahia, em Salvador, ressaltava-se cada vez mais as continuidades entre as práticas africanas e afro-baianas, enquanto no Rio, a mestiçagem racial dominou o discurso identitário. Essa diferença é mencionada pontualmente no livro, mas merece mais espaço, diante do argumento do autor de que o discurso da baianidade nasceu no contexto do projeto de identidade nacional de Getúlio Vargas. Uma maior atenção às diferenças regionais, culturais e demográficas entre o Rio de Janeiro, epicentro do projeto do governo Vargas, e o Nordeste, área periférica, teria fortalecido e complementado essa tese, particularmente no capítulo 4, na discussão sobre o imaginário das letras de músicas veiculadas por gravadoras sediadas no Rio, e no capítulo 5, quando o autor compara a permanência das escolas de samba no Carnaval do Rio de Janeiro com a perda de visibilidade das batucadas e afoxés na folia baiana depois da invenção do trio elétrico. Com relação à edição, o livro teria se beneficiado de uma copidescagem mais rigorosa. Ao tentar separar, capítulo por capítulo, manifestações culturais que na verdade são inter-relacionadas e fazem parte do mesmo momento histórico, frequentemente protagonizadas pelos mesmos atores, a narrativa acaba se repetindo, sem que essas repetições sejam sinalizadas no texto. Em alguns lugares, as notas de rodapé não dão conta dos dados apresentados, deixando o leitor sem saber de onde veio a informação.

Por outro lado, African-Brazilian culture and regional identity in Bahia, Brazil brinda o leitor com um impressionante volume de dados originais, resultado de farta pesquisa que inclui várias fontes pouco utilizadas por outros estudiosos do tema. Além de trazer material dos diários de campo dos Herskovits, como foi mencionado acima, há também dados da documentação da Irmandade do Senhor do Bonfim e da correspondência do cônsul dos Estados Unidos na Bahia. As discussões sobre a crescente importância da Lavagem do Bonfim na identidade da Bahia e sobre as batucadas e os afoxés no Carnaval dos anos 1940 representam contribuições originais ao estudo dessas questões, e os argumentos são bem documentados com dados levantados em jornais da época. Diferente de alguns brasilianistas, cujo uso de fontes secundárias tende a privilegiar a produção estrangeira, Scott Ickes demonstra um excelente conhecimento do trabalho de pesquisadores no Brasil, inclusive de publicações recentes ou de difícil acesso. Por todos esses motivos, African-Brazilian culture and regional identity in Bahia, Brazil representa uma contribuição muito bem-vinda à história social da Bahia na época de Getúlio Vargas, de forma geral, e à literatura sobre o tropo da baianidade, especificamente. 